\title{
The influence of pre-fermentative treatments on the volatile, chromatic features, organic acids and phenolic content of Fetească albă Romanian wine
}

\author{
Ana-Maria Moroşanu ${ }^{1}$, Valeriu V. Cotea ${ }^{1, a}$, Camelia Elena Luchian ${ }^{1}$, Marius Niculaua ${ }^{2}$, Cintia Colibaba ${ }^{1}$, and Alexandru \\ Cătălin Tarţian ${ }^{1}$ \\ ${ }^{1}$ Faculty of Horticulture, University of Agricultural Sciences and Veterinary Medicine Iaşi, 700490 Iaşi, Romania \\ ${ }^{2}$ Oenological Research Center - Romanian Academy - Iaşi Branch, 700505 Iaşi, Romania
}

\begin{abstract}
The present study evaluates the influence of some pre-fermentative treatments on the volatile content, the chromatic parameters, the total polyphenol index and Folin-Ciocâlteu index of experimental wines obtained from Fetească albă grape variety. Five experimental samples were produced: FA V0 (control sample), FA V1 (sodium bentonite treatment), FA V2 (glutathione treatment), FA V3 (tannin treatment), FA V4 (oenological coal treatment). The use of pre-fermentative treatments show lower values of Folin-Ciocâlteu index and total polyphenol index, excepting sample treated with tannin. Major color differences are found in the sample treated with tannin and oenological coal. Gas-chromatographic analysis reveals the presence of common wine esters, such as: hexanoic acid ethyl ester, ethyl caprylate, ethyl lactate, ethyl caprate, ethyl myristate, ethyl palmitate, that contributes at the accomplishment of the wines from the sensorial point of view. Diethyl malonate, a compound that occurs naturally in grapes has an apple-like odor and it was identified in the control sample and in the samples treated with tannin and oenological coal, being found $\mathrm{n}$ greater quantity in the control sample $(0.02 \mathrm{mmol} / \mathrm{L})$ and the sample treated with coal $(0.03 \mathrm{mmol} / \mathrm{L})$. Another ester, methyl oleate that offers a mild-fatty odor wasn't identified in the control sample, but it was detected in the samples treated with clay, tannin and oenological coal. Using the HPLC method it was also analysed the presence of some organic acids in wine samples.
\end{abstract}

\section{Introduction}

The quality of a typical wine depends not only on the features of the raw material (grapes), but strongly depends on winemaking process and especially the treatments applied.

Wine is a product of both vineyard and the techniques the winemaker uses and occasionally, aspects of the future wine need to be refined or adjusted. In this case prefermentative treatments are used on wines in order to soften a harsh or astringent character, to improve clarity and to create heat stability.

The literature suggests that the use of fining agents should be maintained at the lowest possible dosage in order to achieve the desired effect, but due to the complexity of the chemical structures in wine, different fining agents will more or less effective.

In addition, pre-fermentative techniques may increase the wine's texture, depth of aromas and flavors and age worthiness [1]. The usage of the fining agents at the right time and in the right doses will increase the probability of obtaining a higher quality product [2] and will decrease the necessity of harsh interventions on the future wine.

A major problem encountered particularly in the white wines is the protein stability and represents the most common non biological defect in commercial wines. The

a e-mail: vvcotea@yahoo.com removal of both stable and unstable protein is achieved by using bentonite as a fining agent.

The studies made on the using of bentonite as a fining agentin wine, showed that this treatment reduced with $13 \%$ the total number of volatile compounds of the analyzed wines [3]. However, bentonite fining of musts seems to remove compounds associated with negative wine attributes while it intensifies positively associated compounds [4].

Glutathione is a tripeptide which contains three constitutive amino acids: glutamate, cysteine and glycine. Its biological importance is mainly related to its free sulfhydryl moiety of cysteine residue, which confers unique redox and nucleophilic proprieties [5].

The major functions can be summarized as being an antioxidant, immunity booster and detoxifier. The concentration of glutathione in grapes and later in wines depends on grape varieties, vintage, location and technological practices [6].

However, the treatment of musts with purified glutathione is not allowed by current wine regulation.

Some treatments such as oenological tannin treatment is considerate an "additive" one because instead of removing the offending element, it works by coating to the molecular structure that are responsible for creating the perception of harshness in the wine. While this may seem counterintuitive, the oenological tannin treatment is often 
able to modify the aggressive/harsh character of the treated wine so that the need for further fining can be reduced or even unnecessary. Furthermore the literature supports the idea of using oenological tannins as a help to round out a thin or an aggressive wine and as a layer of protection against oxidation.

Another clarifying agent is the activated coal, which can be used to correct organoleptic issues of wines, to eliminate possible contaminants, to correct the color problems such as excessive browning or pinkness, thanks to his effectiveness at removing non-polar substances, but remains a weak agent concerning the removing water soluble components such as sugar and amino-acids [7]. However, the use of activated coal is avoided because it can strip wine of both desirable and undesirable components.

The aim of the present study is to evaluate the influence of some oenological treatments on the chromatic futures, phenolic indexes, organic acids and principal aroma compounds found in the wines obtained from the Fetească albă grape variety.

\section{Materials and methods}

\subsection{Grape samples}

The present study was carried out for a two years experimental period and it was done on 10 samples of wines obtained from Fetească albă variety.

Fetească albă is an old Romanian grape variety which has always been used for the production of quality white wines. This variety is considerated to be a clonal variation of Fetească neagră.

From the sensory/organoleptic point of view the wines obtained after the winemaking process are characterized by citrus, lime tree-blossom flavors and also by wild flowers, newly mown hay and ripe apricot flavors. Fetească albă wines stand out not only due to their flavors but also because they are characterized by finesse and a special balance.

Regarding the present study, the grapes of Fetească albă were harvest in 2014 and 2015 at full maturity from Copou-Iaşi vineyard. The grapes composition was optimal for obtaining dry quality wines.

\subsection{Wine samples}

The wine samples taken in the experiment were produced in the micro-winery belonging to the Oenological department of the University of Agricultural Sciences and Veterinary Medicine of Iaşi.

Healthy ripe grapes of Vitis vinifera var. Fetească albă were destemmed, crushed and the obtained must was homogenized and divided into five glass vessels of $25 \mathrm{~L}$ for the alcoholic fermentation.

Before fermentation started were used four oenological products: V0-control sample (no pre-fermentative treatment applied), V1-bentonite pre-fermentative treatment, V2-gluthatione pre-fermentative treatment, V3-oenological tannin pre-fermentative treatment, V4-oenological coal pre-fermentative treatment.

The glass vessels were deposited in a controlled temperature room $\left(18^{\circ} \mathrm{C}\right)$, where the must fermented for 10 days. For the alcoholic fermentation process commercial yeasts were used. After completion of alcoholic fermentation process, the wines obtained were filtered using a filtration device (filter Grifo) and sterile boards.

Then, the wines were treated with sulphur dioxide to preserve the samples from microbiological damage and were transferred in $750 \mathrm{ml}$ glass bottles. Bottling was done with a semi-automatic device.

\subsection{Reagents for pre-fermentative treatments}

For the fermentation process were used commercial yeasts (Fermactive $\mathrm{AP}^{\circledR}$ ) and fermentation activators (FermoplusIntegrateur ${ }^{\circledR}$ ). For the pre-fermentative treatments were used the following agents: bentonite Clarit $360^{\circledR}$, glutathione, Tanivin Blanc ${ }^{\circledR}$, Enoanticromos active coal.

After the decarbonisation operation, each sample of wine was submitted to the following analyses: sulfur dioxide, volatile acidity, total acidity, alcoholic strength, reducing substances, total dry matter and non reducing substances. The analyses were done according to OIV methods and the specific literature [7].

\subsection{Folin- Ciocalteu index and total polyphenols index}

The indexes of total polyphenols and Folin-Ciocâlteu were determined by the spectroscopic methods using a Spectrophotometer Analytic Jena S 200.

Folin-Ciocâlteu Index (IFC) is a specific method for the phenolic compounds analysis with reducing properties.

The determination of Folin-Ciocâlteu index is based on the oxidation of phenolic compounds in wine by the FolinCiocâlteu reagent. This reagent consists of a mixture of phosphotungstic acid $\left(\mathrm{H}_{3} \mathrm{PW}_{12} \mathrm{O}_{40}\right)$ and phosphomolybdic acid $\left(\mathrm{H}_{3} \mathrm{PMo}_{12} \mathrm{O}_{40}\right)$. The blue coloration produced has a maximum absorption around $750 \mathrm{~nm}$ (visible light) and it is proportional to the total amount of phenolic compounds OIV - MA- AS2-10).

The index of total polyphenols (IPT) or D280 index is a parameter that describes the content of total phenolic compounds (phenolic acids, tannins, anthocyanins, flavones, etc.) of the wines. The method is based on the strong absorption of ultraviolet light by the benzenic cores, characteristic for the phenolic compounds, with a maximum absorption wavelength at $\lambda=280 \mathrm{~nm}$.

\subsection{Evaluation of chromatic characteristics}

In order to evaluate the chromatic features of the analyzed samples a spectrophotometer Analytic Jena S was used.

The color CIELab 76 is the most complete color model used to describe the colors of the visible spectrum because it allows the specification of the largest number of shades of color that a person could perceive with CIELab values $a^{*} b^{*}$. Therefore, the range of colors based on this model is described as the widest range of reproducible colors of the visible spectrum [8].

Basically the CIELab 76 colour or space system is based on a sequential or continuous Cartesian representation of three orthogonal axes: $L, a$ and $b . L$ represents the clarity, $a$ represents the green/red shades of color and $b$ represents the blue/yellow shades of color. 
Table 1. Physico-chemical parameters of wines obtained through different pre-fermentative treatments.

\begin{tabular}{|c|c|c|c|c|c|c|c|c|c|c|c|}
\hline Sample & $\begin{array}{c}\text { Alc. } \\
\text { (\% vol. })\end{array}$ & $\begin{array}{c}\text { Total acidity } \\
\text { (g tartaric } \\
\text { ac./L) }\end{array}$ & $\begin{array}{c}\text { Volatile acidity } \\
\text { (g acetic } \\
\text { ac./L) }\end{array}$ & $\begin{array}{l}\text { Reducing } \\
\text { subst.(g/L) }\end{array}$ & $\begin{array}{l}\text { T.D.E } \\
(\mathrm{g} / \mathrm{L})\end{array}$ & $\begin{array}{l}\text { N.E } \\
(g / L)\end{array}$ & $\begin{array}{c}\text { Free SO }{ }_{2} \\
(\mathrm{mg} / \mathrm{L})\end{array}$ & $\begin{array}{c}\text { Total SO } \\
(\mathrm{mg} / \mathrm{L})\end{array}$ & $\begin{array}{c}\text { Relative } \\
\text { density }(\mathrm{g} / \mathrm{L})\end{array}$ & $p \mathbf{H}$ & $\begin{array}{l}\text { Conductivity } \chi \\
(\mu \mathrm{S} / \mathrm{cm})\end{array}$ \\
\hline V0 & 12.18 & 6.55 & 0.23 & 0.77 & 19.6 & 18.8 & 38 & 91 & 0.9915 & 3.07 & 1398 \\
\hline V1 & 12.11 & 5.99 & 0.23 & 0.68 & 18.0 & 17.3 & 36 & 89 & 0.9910 & 3.17 & 1546 \\
\hline $\mathbf{V 2}$ & 11.78 & 6.61 & 0.30 & 0.89 & 19.0 & 18.1 & 48 & 107 & 0.9918 & 3.04 & 1515 \\
\hline V3 & 12.20 & 5.63 & 0.25 & 1.49 & 21.6 & 20.1 & 30 & 97 & 0.9925 & 3.34 & 1681 \\
\hline V4 & 11.83 & 6.58 & 0.26 & 1.02 & 17.7 & 16.6 & 38 & 92 & 0.9912 & 3.01 & 1508 \\
\hline$\overline{\mathbf{A 0}}$ & 11.83 & 5.68 & 0.46 & 1.16 & 21.6 & 20.4 & 13 & 72 & 0.9927 & 3.20 & 1528 \\
\hline $\mathbf{A 1}$ & 10.28 & 6.01 & 0.57 & 1.08 & 18.5 & 17.4 & 20 & 85 & 0.9933 & 3.22 & 1590 \\
\hline $\mathbf{A 2}$ & 10.40 & 6.29 & 0.63 & 1.18 & 19.0 & 17.8 & 9 & 75 & 0.9934 & 3.18 & 1620 \\
\hline$\overline{\mathrm{A3}}$ & 9.48 & 5.36 & 0.38 & 1.11 & 17.5 & 16.3 & 9 & 53 & 0.9939 & 3.24 & 1694 \\
\hline A4 & 9.57 & 5.93 & 0.38 & 1.21 & 14.5 & 13.2 & 22 & 70 & 0.9926 & 3.12 & 1424 \\
\hline
\end{tabular}

V0, V1,.., V4- 2014 Fetească albă wine samples.

A0, A1,.., A4- 2015 Fetească albă wine samples.

\subsection{Gas-chromatographic analysis of volatile compounds}

In order to conduct the determination of the aroma fraction, a HS20-GC-MS was used. The system uses as carrier gas the nitrogen and the adsorption material for the stationary phase is the type of resin 2, 6-diphenylene oxide (ITEX).

For the concentrating process of the samples was used a method that takes volatile compounds from the vapor atmosphere and performs the concentration of the vapors on the stationary phase. In this case $7 \mathrm{ml}$ of wine were added in a vial for analysis of vapors (headspace).

The separation column used is a Phenomenex ${ }^{\circledR}$ type FFAP $50 \mathrm{~cm} \times 0.32 \mathrm{~mm}$ ID $\times 0.5 \mu \mathrm{m}$ which is contained in a temperature - controlled oven capable of maintaining temperatures ranging from ambient temperature to temperatures equivalent with a value of $300^{\circ} \mathrm{C}$. For the present study, the working schedule in the oven lasted a total of 41 minutes, reaching a maximum temperature of $240^{\circ} \mathrm{C}$. The injection mode of the sample was a direct one, ensuring a constant carrier gas linear velocity of $18 \mathrm{~cm} / \mathrm{s}$. The operating pressure in the column was $78 \mathrm{kPa}$ and the carrier gas flow rate was a constant of $2 \mathrm{ml} / \mathrm{min}$.

\subsection{HPLC-analysis of the acids}

The analysis of the acids was carried out using a high performance liquid chromatography technique. In this sense a liquid chromatograph Shimadzu series Proeminence LC20 was used.

The chromatographic column presents a pre-column type Security-Guard Ultra cartige UHPLC C18 for the column that have a $4.6 \mathrm{~mm}$ diameter. The mobile phase was given by:

$>$ eluent A: $0.1 \%$ solution of methanol $\left(\mathrm{CH}_{3} \mathrm{OH}\right)$ acidified with trifluoracetic acid (TFA) at a $\mathrm{pH}$ of 2.17

$>$ eluent B: $50 \%$ solution of methanol $\left(\mathrm{CH}_{3} \mathrm{OH}\right)$ acidified with trifluoracetic acid (TFA) at a $\mathrm{pH}$ of 2.22 .

At the temperature of $20^{\circ} \mathrm{C}, 10 \mathrm{ml}$ of sample previously filtered through a nylon filter with size pore of $0.45 \mathrm{~mm}$ was injected into the system. Separation was achieved through a Phenomenex ${ }^{\circledR}$ column type Kinetex having the following characteristics: length $(\mathrm{L}) \times$ diameter (ID) $150 \times 4.6 \mathrm{~mm}$, which is loaded with particles of silan grafted with $2.4 \mu \mathrm{m}$ with a octadecil $96 \AA$ pore column, having a graft capacity of $3 \mu \mathrm{mol} / \mathrm{m}^{2}$.

\section{Results and discussion}

The general physico-chemical parameters of the analyzed wine samples are presented in Table 1. Comparing the wine samples obtained from Fetească albă variety in the year 2014 and those obtained in the year 2015 were found important differences concerning the values of alcoholic concentration.

So if in the case of 2014 Fetească albă wine samples the values of alcoholic strength parameter were superior than the $11 \%$ volume alcohol, in the case of Fetească albă 2015 the values of this parameter were minor than $11 \%$ volume alcohol. Most likely these differences are due to the differenciated climatic conditions of the two years of study: rainfals, solar radiation, temperatures, heat-stroke.

Concerning volatile acidity it is considerated that if a winemaker has done a properly job the finished wines will have a level of acetic acid that varies between 0.3 and $0.5 \mathrm{~g} / \mathrm{L}$, meaning that the bacteria are contributing with 200-400 $\mathrm{mg} / \mathrm{L}$ acetic acid [7].

In the case of Fetească albă wine samples obtained in 2014 it can be observed that the parameter varies between a minimum of $0.23 \mathrm{~g} / \mathrm{L}$ acetic acid for the sample treated with bentonite and a maximum of $0.3 \mathrm{~g} / \mathrm{L}$ acetic acid for the sample treatead with glutathione. For the 2015 Fetească albă wine samples the volatile acidity varies between $0.38 \mathrm{~g} / \mathrm{L}$ acetic acid for the samples treated with coal active and tannin and $0.6 \mathrm{~g} / \mathrm{L}$ for the sample treated with glutathione. The literature specificates that the level of detection known as the aroma threshold, of acetic acid depends on the wine and the sensitivity of the person snifing, but is generally situated between 0.6 and $0.9 \mathrm{~g} / \mathrm{L}$ acetic acid [9]. That being said it can be stated that in the case of 2015 Fetească albă wine sample treated with glutathione there is the probability of perceving the presence of acetic acid.

Total acidity values calculated for the 2014 wine samples were higher than the values calculated for the 2015 wine samples. Thus, the higher value for the 2014 samples was registered for the sample treated with tannin 


\section{Polyphenols index and Folin-Ciocâlteu index}

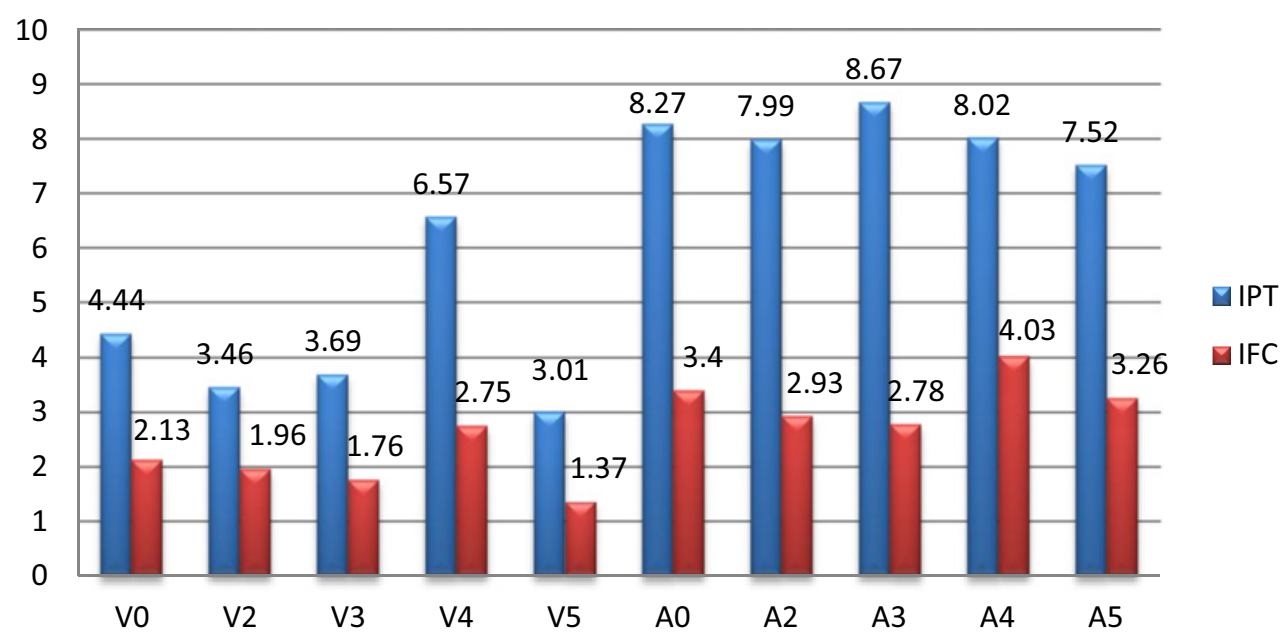

V0, V1,..., V4- 2014 Fetească albăwine samples. A0, A1, .., A4- 2015 Fetească albă wine samples.

Figure 1. Total polyphenols index (IPT) and Folin - Ciocâlteu index (IFC).

(5.63 g/L tartaric acid) and for the 2015 wine sample the higher value was registered for the sample treated with glutathione $(6.29 \mathrm{~g} / \mathrm{L})$.

The active coal treatment had a bigger influence on the non-reductive extract and on the total dry extract values in the sense of reducing them. Regarding the sugars or the reducing substances values, the Fetească albă wine samples 2014 and 2015 can be included in the dry cathegory wines.

The real acidity of the wine or the $\mathrm{pH}$ has impact on almost every aspect of the wine.Thus, it influence the flavor of the wine, the stability, the preciptation process of tartrates, the absorbtion of carbon dioxide and the rate of the fermentation process. Also, the $\mathrm{pH}$ is involved in many of the chemical reactions that take place during and after the alcoholic fermentaion. Refering to the samples of wine under discussion the values of $\mathrm{pH}$ were situated between a minimum of 3.01 and a maximum of 3.34 , which doesn't allow the growth of microorganisms due to the release of fatty acids antimicrobial proprieties.

Observing the values of the total acidity and the values of $\mathrm{pH}$ it can be noticed that in the majority of the wine samples a growth of total acidity determines a decrease of $\mathrm{pH}$, therefore an inverse relation.

The conductivity of the wine is a macroparameter which is influenced not only by the acids present in the analysed environment, but also by others compounds such as: the concentrations of various anionic species, various proteins or enzymes with colloid protective role and the concentration of metal ions which serve the complexing processses. Refering at the analysed samples, the highest values were registered for the samples treated with tannin (1681 $\mu \mathrm{s} / \mathrm{cm}-2014 ; 1694 \mu \mathrm{s} / \mathrm{cm}-2015)$.

The values of the Folin-Ciocâlteu index and the polyphenol index can be examined in the Fig. 1. The pre-fermentative treatments determined two notable variations: the addition of tannin determined a growth
Table 2. Chromatic parameters of the analyzed samples.

\begin{tabular}{|l|c|c|c|c|c|c|}
\hline \multirow{2}{*}{ Samples } & Clarity & \multicolumn{2}{|c|}{ Chromaticity } & Crome & \multirow{2}{*}{$\boldsymbol{\Delta} \mathbf{E}$} & \multirow{2}{*}{$\Delta \mathbf{H}$} \\
\cline { 3 - 4 } & $\mathbf{L})$ & $\mathbf{a}$ & $\mathbf{b}$ & $\mathbf{C}$ & & \\
\hline V0 & 98.53 & -0.20 & 3.63 & 3.63 & - & - \\
\hline V1 & 99.62 & -0.39 & 2.36 & 2.39 & 4.47 & 4.37 \\
\hline V2 & 99.79 & -0.33 & 2.44 & 2.47 & 4.55 & 4.43 \\
\hline V3 & 98.76 & 0.05 & 4.44 & 4.44 & 5.01 & 4.81 \\
\hline V4 & 100.49 & -0.51 & 2.51 & 2.56 & 4.55 & 4.25 \\
\hline A0 & 98.12 & -0.48 & 4.51 & 4.53 & - & - \\
\hline A1 & 97.88 & -0.38 & 4.97 & 4.99 & 4.90 & 4.38 \\
\hline A2 & 98.66 & -0.52 & 4.80 & 4.83 & 4.60 & 4.23 \\
\hline A3 & 97.07 & 0.22 & 7.65 & 7.66 & 7.04 & 4.98 \\
\hline A4 & 97.75 & -0.15 & 5.19 & 5.19 & 5.22 & 4.61 \\
\hline
\end{tabular}

of the indexes and on the other hand the treatment with active coal and bentonite determined a decrease of the two indexes.

The chromatic parameters: L (brighteness coordinate or pshychromatric clarity), a (red-green coordinate), b (yellow-blue coordinate) and C (chromaticity or saturation) were calculated according to the CieLab 76 method and to the registered absorption spectrum of each wine sample. The values are presented in Table 2. In addition to these parameters were calculated other two variables: $\Delta \mathrm{E}$ (the differences of sensations) (10) and $\Delta \mathrm{H}$ (the difference in tonality between two colors), the control sample being the reference sample.

The values of $\mathrm{L}$ parameter show that the wine samples submitted to the bentonite and active coal treatments are the most clear (Table 2). Major color differences were found in the sample 2014 wine sample treated with tannin and in the 2015 control sample were prevailed the redyellow shades of colors instead of green-yellow shades of colors as in the case of others samples. Color saturation values $(\mathrm{C})$ were maintained in small limits of variation 
from a minimum of 0.77 and a maximum of 3.52 . With the increase in $\mathrm{C}$ parameter, changes occur in the color visually inspected, so the samples V3 (treated with tannin) and the 2015 control sample which have the highest saturation values also have distinct shades of colors.

Regarding the values of $\Delta \mathrm{E}$ and $\Delta \mathrm{H}$ parameters, major differences were found in the samples treated with tannin.

Concerning the volatile component of the analyzed wine samples, it will be taking into discussion only the esters and the terpenes. For the volatile compounds analysis it was used GC-MS method and the quantitative expression were made in $\mathrm{mmol} / \mathrm{L}$ according to the standard solution of 4-metil 2-pentanol, determined for each sample.

The esters are the largest qualitative constituents of wines and the formation is strongly dependent upon the yeast strains, the fermentation temperature and the treatments applied [11,12].

Referring to the analyzed wine samples, a number of 29 esters were identified both in the samples processed in 2014 and also in the year 2015. The esters are presented in Table 3. Furthermore, analyzing Table 3, it can be observed that the majority of the esters found in the wine samples are responsible for the "fruity" and "floral" wine odors.

Among the esters that were identified, some of them were detected in bigger concentrations such as: ethyl caprylate, ethyl lactate, ethyl caprate, diethyl succinate, ethyl laurate, ethyl myristate, ethyl palmitate. Ethyl caprylate an ester characterized by a waxy aroma with sweet, fruity, pineapple, apricot odors was detected in bigger quantities in the samples submitted to the prefermentative treatments than in the control samples. Ethyl lactate an ester resulting in the cell carbon metabolism process was present in higher concentrations in the samples obtained in 2014. This ester is usually considerated a wine fault, but in the right concentration it has a positive impact and brings to the wine a strawberry, fruity odor. Ethyl caprate an ester resulted in the degradation process of decanoic acid and characterized by a fruity aroma with sweet, apple, grape odors was identified in larger quantities in the wine samples treated with bentonite.

The coal active treatment is considerated a nonselective treatment which has a harsher impact on wine. However, the GC-MS analysis of wine samples demonstrated that the concentration of some esters increased after applying the coal active treatment, such as: ethyl hexanoate, ethyl 2-hydroxy 4-methylpentanoate, diethyl succinate, diethyl malonate, ethyl carbonate.

The concentrations of ethyl caprate, ethyl stearate, ethyl docosanoate, ethyl saycilate, ethyl phenyl acetate were higher in the samples treated with bentonite and the tannin treatment determined higher concentrations of ethyl heptanoate and ethyl pelargonate.

Analyzing Table 3 it can be observed that some esters such as: isoamylacetate, ethyl heptanoate, isopentylhexanoate, propryloctanoate, ethyl pelargonate, ethyl 2hydroxicaproate, methyl caprate, were present only in the 2015 wine samples and others such as: ethyl cinnamate, diethyl malonate, ethyl stearate, were identified only in the 2014 wine samples. This fact could be a proof that even if the variables of the winemaking process haven't been changed the aroma profile of the wine samples is different due probably to the raw material characteristics (grapes) and chemical changes that take place in the fermentation process which cannot be fully controlled.

Generally, after the GC-MS analysis it can be established the prevalence of the esters resulting in the fatty acid degradation process and the fatty methyl esters resulting in the trans-esterification process of fatty acid esters with methanol. Furthermore, important quantities of esters resulting in the amino-acid degradation process and in the cell carbon metabolism process were identified.

The literature underlines the fact that the terpenic compounds play a significant role in varietal wine aroma because of their characteristic fruity-flowery odor $[13,14,15]$. Profiles of these compounds in the grape are mainly dependent on the variety and their presence in wines depends in winemaking process. Referring to the Fetească albă wine samples analyzed there were found several terpenoids compounds, mainly (Table 4): acyclic monoterpenes (linalool, citronellol, nerol, geraniol, lavandulol), acyclic sesquiterpennes (nerolidol), monocyclic monoterpenes $(\alpha$-terpenoids such as isomyrcenol and derivates (nerolidyl acetate, geranial diethyl acetal). As in the case of esters the presence of terpenes in the analyzed wine samples was quantified in $\mathrm{mmol} / \mathrm{L}$. Some terpenoid compounds such as: isomyrcenol and lavandulol were present only in the 2014 wine samples and others such as: nerol, geraniol, $\alpha$-terpineol, geranial diethyl acetal were identified only in the 2015 wine samples.

The additive treatment with tannin determined higher concentrations of linalool and citronelol in the analyzed wine samples. Nerol and isomyrcenol, two terpenoids characterized by a floral aroma with citrus, green, lemon flavors, were identified only in the 2015 control sample, meaning that the treatments applied influenced in a negative way their presence in the wines.

Curiously is the fact that even if the coal active treatment is known as a harsher, non-selective treatment that "strips" the wine from his varietal aroma, in the present study this hypothesis is not completely validated. Thus, $\alpha$-terpineol an monocyclic monoterpene characterized by an lilac, citrus, woody odor-like was identified only in the 2015 wine sample treated with coal active and another terpene such as nerolidol and geraniol were identified in bigger quantities in the samples treated with active coal.

The presence of the acetals in wine contributes at the modulation and at the smoothing process of wine aroma [16]. Geranial diethyl acetal a derivate characterized by a citrus aroma with fresh, lemon, green odors was identified only in the 2015 control sample $(0.01 \mathrm{mmol} / \mathrm{L})$. Nerolidyl acetate an derivate characterized by an floral aroma with sweet, citrus, woody, freesia odors was detected in the control samples and in bigger quantity in the 2015 wine sample treated with tannin $(0.10 \mathrm{mmol} / \mathrm{L})$.

Acid determination it is an important point for the characterization of wine composition evolution with implication in chemical and biochemical processes. The grape contains most of the acids involved in the glycolitic and shikimic acid pathways as well as in Krebs and glyoxylic acid cycles, the rest remaining unmodified, being transmitted in wine [7].

In Table 5 are presented the values of the organic acids obtained using the HPLC analysis. Natural acids have the freshest, purest tastes, tartaric acid and malic acid being 
Table 3. Esters identified in the analyzed wine samples ( $\mathbf{m m o l} / \mathbf{L})$.

\begin{tabular}{|c|c|c|c|c|c|c|c|c|c|c|}
\hline Esters & V0 & V1 & V2 & V3 & V4 & A0 & A1 & A2 & A3 & A4 \\
\hline Ethyl hexanoate & - & 0.01 & - & - & 0.01 & 0.05 & 0.05 & 0.07 & 0.08 & 0.09 \\
\hline Ethyl caprylate & 0.10 & 0.31 & 0.29 & 0.11 & 0.25 & 8.82 & 14.58 & 11.11 & 13.19 & 14.80 \\
\hline Ethyl lactate & 1.92 & 2.98 & 3.71 & 2.19 & 3.13 & 1.72 & 0.00 & 0.69 & 2.36 & 8.59 \\
\hline $\begin{array}{l}\text { Pentanoic acid, 2-hydroxy- } \\
\text { 4-methyl-, ethyl ester }\end{array}$ & - & - & 0.04 & 0.02 & 0.07 & - & 0.01 & - & 0.01 & 0.02 \\
\hline Ethyl caprate & 0.09 & 0.31 & 0.18 & - & 0.11 & 4.83 & 10.57 & 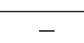 & 7.22 & 7.89 \\
\hline Ethyl benzoate & 0.15 & 0.15 & 0.18 & 0.16 & 0.11 & 0.22 & 0.18 & 0.17 & 0.18 & 0.22 \\
\hline Diethyl succinate & 0.59 & 0.44 & 0.75 & 0.43 & 1.35 & 0.23 & 0.08 & 0.13 & 0.24 & 0.29 \\
\hline Ethyl laurate & 0.03 & 0.07 & 0.06 & 0.05 & - & 0.32 & 0.74 & 0.55 & 3.33 & 3.08 \\
\hline Ethyl nicotinate & 0.02 & 0.03 & 0.02 & 0.02 & - & 0.04 & - & - & 0.01 & 0.04 \\
\hline Isoproprylmyristate & - & 0.04 & - & 0.02 & - & - & - & 0.04 & 0.31 & - \\
\hline Ethyl myristate & 0.09 & 0.18 & 0.32 & 0.20 & 0.19 & 0.9 & 0.52 & 1.24 & 2.37 & 1.09 \\
\hline Ethyl heptadec-9-enoate & 0.07 & 0.02 & 0.06 & - & 0.06 & 0.04 & - & 0.09 & - & - \\
\hline Diethyl malonate & 0.02 & - & 0.01 & 0.01 & 0.03 & - & - & - & - & - \\
\hline Ethyl palmitate & 0.09 & 0.83 & 0.29 & 1.78 & 1.17 & 1.60 & 0.59 & 1.91 & 0.82 & 2.00 \\
\hline Ethyl cinnamate & 0.01 & - & 0.01 & - & 0.01 & - & - & - & - & - \\
\hline Methyl palmitate & 0.35 & 0.01 & 0.9 & - & 0.04 & - & - & - & - & - \\
\hline Ethyl stearate & 0.03 & 0.08 & 0.07 & 0.07 & 0.06 & - & - & - & - & - \\
\hline Ethyl carbonate & - & - & - & - & 1.4 & - & - & - & - & - \\
\hline Isoamyl acetate & - & - & - & - & - & - & - & 0.46 & 0.35 & 0.42 \\
\hline Ethyl heptanoate & - & - & - & - & - & 0.02 & - & - & 0.04 & 0.01 \\
\hline Isopentylhexanoate & - & - & - & - & - & - & - & 0.11 & 0.08 & 0.03 \\
\hline Propryloctanoate & - & - & - & - & - & 0.02 & 0.01 & 0.02 & - & 0.04 \\
\hline Ethyl pelargonate & - & - & - & - & - & 0.33 & - & 0.30 & 0.46 & 0.35 \\
\hline Butyl caprylate & - & - & - & - & - & 0.03 & - & 0.03 & 0.06 & 0.08 \\
\hline Methyl caprate & - & - & - & - & - & - & - & 4.65 & - & - \\
\hline $\begin{array}{l}\text { Octanoic acid, } \\
\text { 3-methylbutyl ester }\end{array}$ & - & - & - & - & - & 0.16 & 0.15 & 0.28 & 0.28 & 0.47 \\
\hline Ethyl 9-decenoate & - & - & - & - & - & 0.11 & 0.01 & 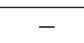 & 0.01 & - \\
\hline Ethyl pHenyl acetate & - & - & - & - & - & 0.06 & 0.27 & 0.15 & 0.12 & - \\
\hline Ethyl salycilate & - & - & - & - & - & 0.03 & 0.04 & 0.02 & 0.02 & 0.03 \\
\hline
\end{tabular}

V0, V1,.., V4- 2014 Fetească albă wine samples.

A0, A1,.., A4- 2015 Fetească albă wine samples.

Table 4. Terpenic compounds found in the analyzed wine samples ( $\mathbf{m m o l} / \mathbf{L})$.

\begin{tabular}{|l|c|c|c|c|c|c|c|c|c|c|}
\hline Terpenes & V0 & V1 & V2 & V3 & V4 & A0 & A1 & A2 & A3 & A4 \\
\hline Isomyrcenol & 0.04 & - & - & - & - & - & - & - & - & - \\
\hline Linalool & 0.01 & 0.01 & - & 0.02 & 0.01 & 0.04 & 0.03 & 0.03 & 0.08 & 0.07 \\
\hline Citronellol & 0.01 & 0.01 & - & 0.01 & - & 0.01. & 0.02 & 0.02 & 0.03 & 0.02 \\
\hline Nerolidyl acetate & 0.02 & - & - & - & - & 0.02 & - & - & 0.10 & - \\
\hline Nerolidol & - & 0.01 & 0.01 & - & - & - & - & - & - & 0.04 \\
\hline Lavandulol & - & 0.02 & - & - & - & - & - & - & - & - \\
\hline Nerol & - & - & - & - & - & 0.01 & - & - & - & - \\
\hline Geraniol & - & - & - & - & - & - & - & - & 0.01 & 0.03 \\
\hline Geranial diethyl acetal & - & - & - & - & - & 0.01 & - & - & - & - \\
\hline$\alpha$-terpineol & - & - & - & - & - & - & - & - & - & 0.13 \\
\hline
\end{tabular}

V0, V1,.., V4- 2014 Fetească albă wine samples; A0, A1,.., A4- 2015 Fetească albă wine samples.

the major grapes acids, with citric acid being among the minor ones.

Tartaric acid is a specific acid for grapes and an important one because together with his potassium and calcium salt controls the effective acidity $(\mathrm{pH})$ and finally contributes to a wine's color, aseptic stability and taste. Referring to the wine samples analyzed, it has been observed that the tannin treatment determined the lowest values for the tartaric acid $(3.90 \mathrm{mg} / \mathrm{L}-2014 ; 5.39 \mathrm{mg} /$ L-2015) and the active coal treatment determined the highest values (7.13 mg/L-2014; $7.39 \mathrm{mg} / \mathrm{L}-2015)$.
Malic acid was identified in higher concentrations in the 2014 wine samples where the values varied between a minimum of $2.22 \mathrm{mg} / \mathrm{L}$ (bentonite treatment) and a maximum of $2.79 \mathrm{mg} / \mathrm{L}$ (tannin treatment). In the 2015 wine samples this acid varied between a minimum of $1.20 \mathrm{mg} / \mathrm{L}$ (active coal treatment) and a maximum of $1.98 \mathrm{mg} / \mathrm{L}$ (glutathione treatment). The concentration of citric acid did not vary within wide limits for the analyzed samples.

Ascorbic acid naturally present in lactone form constitutes a redox system assaying in this way the 
Table 5. Organic acids found in the analyzed wine samples.

\begin{tabular}{|l|c|c|c|c|c|c|c|c|c|c|}
\hline Acids & V0 & V1 & V2 & V3 & V4 & A0 & A1 & A2 & A3 & A4 \\
\hline oxalic acid $(\mathrm{mg} / \mathrm{L})$ & nd & nd & nd & 0.06 & nd & 0.06 & 0.05 & 0.05 & 0.06 & nd \\
\hline tartaric acid $(\mathrm{mg} / \mathrm{L})$ & 6.40 & 6.55 & 6.86 & 3.9 & 7.13 & 5.66 & 5.92 & 5.62 & 5.39 & 7.39 \\
\hline malic acid $(\mathrm{mg} / \mathrm{L})$ & 2.44 & 2.22 & 2.26 & 2.79 & 2.48 & 1.62 & 1.73 & 1.98 & 1.93 & 1.20 \\
\hline ascorbic acid $(\mathrm{mg} / \mathrm{L})$ & 0.02 & 0.02 & 0.01 & 0.01 & 0.01 & nd & nd & nd & nd & 0.01 \\
\hline shikimic acid $(\mu \mathrm{g} / \mathrm{L})$ & 24.00 & 24.00 & 24.00 & 42.00 & 24.00 & 12.00 & 12.00 & 12.00 & 12.00 & 18.00 \\
\hline lactic acid $(\mathrm{mg} / \mathrm{L})$ & 0.48 & 0.50 & 0.47 & 0.50 & 0.50 & 0.71 & 0.53 & 0.56 & 0.62 & 1.60 \\
\hline acetic acid acetic $(\mathrm{mg} / \mathrm{L})$ & 0.60 & 0.34 & 0.32 & 0.26 & 0.39 & 0.27 & 0.27 & 0.27 & 0.47 & 0.30 \\
\hline citric acid $(\mathrm{mg} / \mathrm{L})$ & 0.52 & 0.42 & 0.42 & 0.43 & 0.46 & 0.55 & 0.55 & 0.57 & 0.57 & 0.51 \\
\hline succinic acid $(\mathrm{mg} / \mathrm{L})$ & 1.05 & 1.06 & 1.06 & 1.13 & 1.07 & 1.12 & 1.05 & 1.07 & 1.08 & 1.22 \\
\hline fumaric acid $(\mu \mathrm{g} / \mathrm{L})$ & 10.00 & 10.00 & 10.00 & 10.00 & 10.00 & 10.00 & 10.00 & 10.00 & 10.00 & 10.00 \\
\hline
\end{tabular}

nd - not detected; V0, V1,.., V4- 2014 Fetească albă wine samples; A0, A1,.., A4- 2015 Fetească albă wine samples.

protection of phenols from oxidation. In the analyzed samples this acid was found in minor concentrations and in some samples was missing.

Oxalic acid was present only in the 2014 wine sample treated with tannin and almost in all the 2015 wine samples, excepting the sample treated with active coal. The active coal treatment determined higher concentrations of lactic acid in the wine samples. The concentrations of acetic acid were minor in the 2014 wine samples submitted to pre-fermentative treatments than the 2014 control sample.

The shikimic acid was identified in higher concentrations in the 2014 wine samples and the fumaric acid an natural acid present in the majority of the fruits and vegetables and a part of every living cell metabolism didn't suffer fluctuations being found in concentration of $10 \mathrm{mg} / \mathrm{L}$ in each sample wine.

\section{Conclusion}

Following the results of the physico-chemical characteristics, the considered samples could be included in the category of white dry wines. Furthermore, it could be stated that the tannin treatment and the coal active treatment had the highest influence on the $\mathrm{pH}$ and on the conductivity of the wine samples. Thus, the treatment with tannin determined the highest values of the two parameters and the coal active treatment determined the lowest ones.

Comparing with the control sample, the values of the phenolic indexes increased after applying the treatment with tannin and glutathione. As expected compared to the control sample tone difference were observed in the case of tannin addition.

The GC-MS analysis revealed in the analyzed wine samples the predominance of the esters resulting from the fatty acid degradation process. Also it was observed the presence of the fatty acid methyl esters resulting in the trans-esterification process of acid esters with methanol. In addition, it was observed the presence in higher quantities of the acyclic monoterpenes.

As expected, a correlation between the presence of tartaric acid and $\mathrm{pH}$ was found, so the lowest values of tartaric acid were determined on the samples with the highest values of $\mathrm{pH}$ (tannin treatment) and highest values of tartaric acid were found in the samples with the lowest $\mathrm{pH}$ values (coal active treatment).

\section{References}

[1] G. Chieppa, R. Lovino, M. Savino, P. Limosani, S. Suriano, G. Ceci and R. Scazzariello, The 31-st Congresse Mondiale OIV, Verona, 15-20 june, (2008)

[2] D.V. Cotea, C. Zănoagă, V.V. Cotea, Tratat de oenochimie, Bucureşti, Editura Academiei Romane 1, (2009)

[3] A.L.,Falqué, Eur. Food Res. Technol. 225, 553 (2007)

[4] J.F. Harbertson, G.P. Parpinello, H. Heymann, M.O. Downey, Food Chem. 131, 999-1008 (2011)

[5] M.J. Penninckx, Enzyme Microb. Technol. 26, 737-742 (2000)

[6] V.F. Cheynier, J.M. Souquet, M. Moutounet, Am. J. Enol. Vitic. 40, 320-324 (1989)

[7] P. Ribereau-Gayon, Y. Glories, A. Maujeanand, D. Dubourdieu, Handbook of enology. The chemistry of wine: Stabilization and treatments vol. 2, (Ed Chichester Wiley, U.K., 2006)

[8] H. Gernot, CieLab Color Space, (Website book, 2013)

[9] R.S. Jackson, Wine tasting: A professional handbook, (Ed. Elsevier Academic Press, U.K., 2002)

[10] G. Odăgeriu, C. Zamfir, V.V. Cotea, I. Buzilă, Horticulture Series Journal, 48, 339-346 (2005)

[11] E. Killian, C.S. Ough, Am. J. Enol. Vitic. 301-305 (1979)

[12] I. Papathanasiou, R. Selvagini, M. Servili, A. Vaughan-Martini, I.G. Roussis, Food Sci. Technol. Res. 12, 194-198 (2006)

[13] J.S. Camara., P. Herbert, J.C. Marques, M.A. Alves, Anal. Chim. Acta, 513, 203-207 (2004)

[14] A. Rapp, H. Mandery, Experientia, 42, 873-884 (1986)

[15] P.J Williams, C.R. Strauss, B. Wilson, J. Agric. Food Chem. 28, 766-771 (1980)

[16] H. Maarse, Volatile compounds in food and beverages, (Ed. Marcel Dekker Inc., New York, 1991) 